Revista Bioética

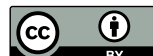

Print version ISSN 1983-8042 On-line version ISSN 1983-8034

Rev. Bioét. vol.28 no.3 Brasília Jul./Set. 2020

Doi: 10.1590/1983-80422020283405

\title{
ATUALIZAÇÃO
}

\section{A ética do cuidado do outro e a bioética ambiental}

Castor Bartolomé Ruiz ${ }^{1}$, Joelson de Campos Maciel ${ }^{1}$

1. Programa de Pós-Graduação em Filosofia, Departamento de Direitos Humanos e Violência, Governo e Governança, Universidade do Vale do Rio dos Sinos, São Leopoldo/RS, Brasil.

\section{Resumo}

Este artigo analisa os desdobramentos da instrumentalização do Aufklärung (Iluminismo) em relação ao agir humano sobre o meio ambiente. Destacam-se as críticas de Hans Jonas à máxima kantiana "sapere aude", a qual impulsionaria a perspectiva de saber como poder ilimitado sobre a natureza. Jonas propõe nova ética que considere a interpelação das gerações futuras como critério para utilizar tecnologias que afetem a natureza. Sua proposta abre nova perspectiva de ética como cuidado do Outro e de bioética como cuidado da vida. A pesquisa se baseou na concepção frankfurtiana de crítica à razão instrumental.

Palavras-chave: Bioética. Meio ambiente. Natureza. Responsabilidade social. Direitos humanos.

\section{Resumen}

\section{La ética del cuidado del otro y la bioética ambiental}

En este artículo se analizan los avances de la instrumentalización de la Aufklärung (llustración) en relación con la acción humana sobre el medio ambiente. Se destaca la crítica de Hans Jonas a la máxima kantiana "sapere aude", que impulsaría la perspectiva de conocer como un poder ilimitado sobre la naturaleza. Jonas propone una nueva ética, que considera el cuestionamiento de las generaciones futuras como un criterio para utilizar las tecnologías que afectan a la naturaleza. Su propuesta abre una nueva perspectiva de la ética como cuidado del Otro y de la bioética como cuidado de la vida. La investigación se basó en el concepto francés de la crítica de la razón instrumental. Palabras clave: Bioética. Ambiente. Naturaleza. Responsabilidad social. Derechos humanos.

\section{Abstract}

The ethics of caring for others and environmental bioethics

This article analyzes the unfolding of instrumental rationality of the Aufklärung (Enlightenment) regarding human action over the environment. The study highlights Hans Jonas' criticisms of Kant's sapere aude maxim, which would support a perspective of knowledge as unlimited power over nature. Hans Jonas, on the other hand, proposes a new ethic, which considers the demands of future generations as a criterion for the use of technologies that may affect nature. His proposal can be used to develop a new perspective on ethics as care for the Other and bioethics as care for life. As a methodological basis, we used the Frankfurtian criticism of instrumental reason.

Keywords: Bioethics. Environment. Nature. Social responsibility. Human rights. 
O desenvolvimento tecnológico trouxe para esta geração poder inédito: a possibilidade de impactar a vida do planeta a ponto de torná-la insustentável. Essa nova condição impõe a urgência de pensar princípios para uma nova ética. Isso porque, tradicionalmente, a ética tinha como referência aqueles com quem se convivia no presente, mas a realidade atual traz a responsabilidade também para com as gerações futuras. Isso exige pensar alguns deslocamentos na ética tradicional, centrada no eu, na pura autonomia do sujeito, no sapere aude kantiano, a fim de elaborar perspectiva cujo referente seja o Outro.

Trata-se de ética da alteridade, que supera a pura noção de autonomia como critério da ação e tem a responsabilidade para com o Outro como critério último do bem ou mal. Esta perspectiva impõe também elaborar o sentido e os princípios de uma bioética ambiental que perceba a natureza como alteridade da qual depende toda a vida no planeta, inclusive a humana, e não como objeto inerte oferecido à exploração ilimitada. A natureza nos interpela e demanda responsabilidade e cuidado. Como as futuras gerações, ela é o que se pode chamar de "Outro".

\section{Crise ética do sapere aude diante do domínio da vida}

Na década de 1780, Kant publica o opúsculo Beantwortung der Frage: Was ist Aufklärung? (“Resposta à pergunta: o que é Iluminismo?"), no qual afirma que o lluminismo representa a emancipação do conhecimento humano, dado que até então a humanidade teria sido como um menor de idade, incapaz de julgar sem um referencial preso a outra entidade. De acordo com Temple, para Kant o que faltava não era o conhecimento em si, mas a direção e coragem de servir-se de si mesmo sem a direção de outrem ${ }^{1}$.

No mesmo texto, Kant cita o mote sapere aude ("ouse saber") mais como ordem do que como salto em terreno obscuro. Ainda segundo Temple, Foucault aponta os três elementos que segundo Kant levarão à emancipação: a vontade, a autoridade e o uso da razão ${ }^{2}$. Tais recursos exemplificam bem a demolição global empreendida pelo Aufklärung (Iluminismo).

Por meio da razão, a vontade deve alforriar-se e exercer plenamente sua autonomia, saindo da preguiça e mesmo da covardia de não querer decidir por si mesma, deixando de se esconder em autoridades exteriores, especialmente as teologais. Contudo, Kant, na referida provocação "o que é lluminismo?", distingue dois tipos de razão. A primeira, de uso privado, é passiva, submissa a regras estabelecidas na sociedade e age em favor desta, cumprindo o seu papel finalístico de preservá-la. A segunda é a razão de uso público, crítica, livre pensadora, que tem liberdade para se expressar justamente porque não cumpre função específica na sociedade, podendo censurar inclusive eventuais erros do serviço estatal a que está obrigada a razão no uso privado. Mas mesmo essa de uso público tem limites: deve-se validá-la diante da razão universal, ou seja, guarda-se aplicação coerente, de tal forma que o julgamento se torna possível em toda parte e por si mesmo, sem necessidade de depender de mais ninguém - trata-se de subjetivismo, quando se obedece à razão universal.

Essa maneira kantiana de ver a razão por ela mesma, no caminho do esclarecimento emancipatório, regulando-a a partir do sujeito, inaugura a filosofia transcendental. Trata-se de espécie de revolução copernicana na filosofia. O indivíduo passa a editar as leis do conhecimento e submete o objeto (não mais o contrário), revestindo o Aufklärung de autoridade o bastante para não somente instaurar uma nova era no pensamento, mas também tornar o humano o ser supremo em todo o processo do conhecimento, de modo a, finalmente, demolir o ancien régime em todos os seus aspectos.

O Aufklärung procurava usar a razão para emancipar o ser humano. O Iluminismo, contudo, tomou diversas direções, já que Kant não percebeu que há diversos modelos de racionalidade - perpassada pela cultura e por interesses sociais. Daí deriva que o ideal originário de emancipação kantiano se desdobra também em racionalidade instrumental, na qual a própria razão se torna meio eficiente de dominação.

Seguindo a ordem dada (sapere aude), livre de interferências divinas ou outras heteronomias, contava-se mais com a razão instrumental e menos com a techné virtuosa. Ademais, acreditava-se que os recursos naturais eram infinitos, tal qual a capacidade racional humana de absorvê-los. A máxima antropocêntrica serviu perfeitamente para a instrumentalização do Aufklärung, em particular para a exploração predatória dos recursos naturais. A mesma visão lógica justificou a autorregulação do mercado pela divisão do trabalho com o argumento da existência de uma racionalidade natural inerente ao sistema de produção, capaz, como espécie de mão invisível, de se autorregular ${ }^{3}$.

No viés instrumental da Aufklärung, a máxima kantiana sapere aude foi reinterpretada cada vez mais não só como "ouse saber", mas "ouse dominar". 
O princípio formulado por Bacon ${ }^{4}$ de que "saber é poder" colonizou a racionalidade moderna. Esse deslizamento do saber para o poder, principalmente na forma do benefício útil, gerou a matriz ética do narcisismo como domínio do outro, que legitima o interesse individual como motor moral de todas as ações. Nessa ética, a aspiração ao benefício próprio culmina em espécie de hedonismo naturalizado.

O ideal kantiano de emancipação pelo sapere aude não se concretizou, ou, se o foi, fê-lo às avessas. Assim, a partir da segunda metade do século XX tomou-se consciência de que o Aufklärung havia parido a racionalidade instrumental antropocêntrica, especialmente na relação predadora com a natureza, vista como objeto neutro e com recursos infinitos. Como exemplo de crítica a essa lógica surge a expressão "crise no meio ambiente", considerada a culminação de todas as outras crises, dentre elas a do desenvolvimento e a da economia ${ }^{5}$.

Contudo, a poluição ambiental somente se torna fonte de preocupação quando transpõe as fronteiras dos Estados-nação e passa a atrapalhar o próprio projeto desenvolvimentista. A dimensão desse problema, além de ameaçar a permanência da humanidade na Terra, trouxe a necessidade de rediscutir o conceito de soberania, já que a antiga teoria do domínio reservado - fundada no longínquo Tratado de Westfália, que encerrou a Guerra dos Trinta Anos entre França e Inglaterra (1618-1648) não servia para solucionar a crise. 0 tratado estabeleceu que o Estado seria soberano em seu território, mas um problema como o da poluição transfronteiriça ultrapassa esse entendimento ${ }^{6}$.

O marco dessa mudança de pensamento foi a sentença arbitral do caso Fundição Trail, entre Estados Unidos e Canadá, em 1941, que definiu: nenhum Estado tem o direito de usar ou de permitir o uso de seu território de tal modo que cause dano em razão do lançamento de emanações no território de outro ${ }^{7}$. Trata-se de verdadeiro princípio do direito internacional do meio ambiente, pois impôs limites claros à soberania sob o ponto de vista da máxima kantiana da reciprocidade.

Outro marco importante para o direito internacional do meio ambiente e sua aproximação com os direitos humanos - pautados na Declaração Universal dos Direitos Humanos, de 10 de dezembro de 1948 - foi o processo de "africanização" da Organização das Nações Unidas (ONU) na década de $1960^{6,8}$. Os países africanos, recentemente descolonizados, pela primeira vez puderam se expressar livremente na Assembleia Geral da ONU, com peso igual de voto em relação aos demais membros, vários deles antigos colonizadores.

A partir de então, foram sendo criados sistemas de proteção ambiental que se comunicavam com os direitos humanos, até que o conceito de "meio ambiente humano" passa a se expandir ${ }^{6}$, a partir da Conferência das Nações Unidas sobre o Meio Ambiente Humano, realizada em Estocolmo em junho de $1972^{\circ}$, para incluir também a defesa das futuras gerações ${ }^{10}$. 0 processo seguiu com o Relatório Brundtland ${ }^{11}$, de 1987, e, finalmente, com a Conferência das Nações Unidas sobre o Meio Ambiente e o Desenvolvimento, realizada no Rio de Janeiro em 1992, que sedimentou, além da sustentabilidade, o tema do direito ao desenvolvimento como princípio global ${ }^{12}$.

Assim, da década de 1970 em diante, percebe-se a união entre direitos humanos e proteção do meio ambiente, na medida em que o Estado se mostrou falho em resolver problemas ambientais e sociais. 0 novo pensamento foi sendo moldado pela legítima representação dos interesses sociais, gerando o que Morand-Deviller ${ }^{13}$ chama de "norma de proximidade", permeada de significado ético de dever e planejamento para o desenvolvimento sustentável. Os princípios dessa norma são a precaução, considerada como a proteção da natureza sempre que houver incerteza científica quanto à sua exploração, e o crescimento socioeconômico sem esgotar recursos naturais ${ }^{14}$.

Nesse período, constata-se a crise ambiental, causada pelas sucessivas e gigantescas intervenções no meio ambiente, que passam pela pródiga aplicação de venenos para o controle de pragas e pelo aumento exponencial das "pegadas ecológicas", conforme relatado nos documentos produzidos pelo Clube de Roma, organização não governamental criada na década de $1960^{14}$, pela Convenção de Estocolmo ${ }^{9}$, e depois no Relatório Brundtland ${ }^{11}$. Neles, pode-se perceber que a qualidade de vida está sendo afetada rapidamente e o próprio crescimento populacional tornou-se um dos fatores do agravamento desse problema $^{15}$. Pela primeira vez, chegou-se à conclusão de que os desastres ambientais poderiam comprometer não somente a biodiversidade, mas a própria vida humana de forma irreversível.

A crise foi gerada pelo viés instrumental da autonomia da vontade, que, com base na racionalidade kantiana, considera o ser humano separado da natureza ${ }^{16}$. A instrumentalização do Aufklärung transformou o planeta em imenso terreno baldio, gratuito e sem propósito, preparado para a dominação humana dentro da técnica que, acreditava-se, caminhava em progresso ininterrupto ${ }^{16}$. 
A contraposição do antropocentrismo arrogante aos valores da natureza ${ }^{17}$ é campo espinhoso para a ética. Trata-se, em outras palavras, do ser humano como fim em si mesmo (Kant) versus a natureza com valores em si mesma. Assim, afloraram novos questionamentos éticos: deve ser a natureza preservada porque possui valores intrínsecos? Ou a humanidade precisa explorá-la? Como fazer para poupar a biodiversidade quando olhamos a espécie humana como centro de tudo, em postura especista, de quem se considera no direito de explorar e escravizar todos os não humanos?

Esse debate é extremamente importante, sobretudo quando se vê o modo distorcido com que se tem empregado o termo "desenvolvimento sustentável". O conceito se transformou em novo argumento da racionalidade instrumental para fundir, no atual modelo capitalista, a preservação do meio ambiente e o crescimento ilimitado da produção e do consumo, como se houvesse demanda infinita por recursos naturais - o que é quase um deboche metafísico ${ }^{18}$.

A racionalidade instrumental gerou uma cultura individualista e hedonista, com graves consequências sobre o conjunto da vida do planeta Terra. A crise ambiental é um dos desdobramentos dessa razão utilitária. No entanto, o próprio problema do narcisismo ético estimulou o desenvolvimento do conceito de bioética ambiental. Dentre os diversos pensadores que se confrontaram com a herança "maldita" do antropocentrismo, destaca-se Hans Jonas ${ }^{19,20}$, que propôs uma ética aplicada ao meio ambiente.

\section{Hans Jonas e o conscius aude}

Como visto, na década de 1970 a defesa dos direitos humanos se uniu à defesa do meio ambiente, questionando a percepção da Terra como grande zoológico ou museu a céu aberto para fins de exploração instrumental. Essa crescente museificação do mundo e da natureza ${ }^{21}$ teve seu contraponto na preocupação com a transgeracionalidade dos direitos humanos e ambientais, para que as futuras gerações tivessem acesso a meio ambiente ecologicamente equilibrado.

O Outro que ainda não está entre nós, as futuras gerações, nos interpela eticamente ${ }^{22}$. Somos a primeira geração que pode impactar irreversivelmente a vida do planeta Terra, e esse poder traz nova responsabilidade. A interpelação do Outro está presente na concepção de ética ambiental, que desconstrói o narcisismo individualista inerente à racionalidade instrumental da Aufklärung.
Concomitantemente a esse movimento da ética ambiental nascente, na década de 1970 iniciou-se a discussão sobre os direitos do enfermo, antes visto como menor de idade, no sentido kantiano. O paciente era considerado "alienado", absolutamente entregue às mãos do médico, por sua vez onisciente da arte da medicina. Essa visão gerava abusos e experimentos os mais atrozes, sobretudo em sujeitos mais vulneráveis, como pobres, negros ou pessoas com deficiência mental.

Segundo Junges ${ }^{23}$, como reação, juntando-se à onda de movimentos civis nos Estados Unidos, em meados do século XX surge a Carta dos Direitos do Enfermo. $O$ documento introduziu o "consentimento informado" nas técnicas clínicas, para que o doente não ficasse totalmente alheio ao tratamento. Nesse período surge também a bioética, ramo da antropologia moral que passou a cuidar de desafios até então invisíveis ${ }^{23}$.

Com a bioética evolui a ética ambiental, tipicamente biocêntrica ${ }^{24}$, surgindo, inclusive, a bioética ambiental, que amplia a discussão tanto do antropocentrismo quanto do biocentrismo, buscando ligá-los ${ }^{25}$. A Declaração Universal sobre Bioética e Direitos Humanos (DUBDH), promulgada em 2005 pela Unesco ${ }^{26}$, é outro marco importante dessa visão ampliada de antropocentrismo, comparável à Convenção de Estocolmo para o meio ambiente e a defesa dos direitos humanos.

Em Estocolmo, o ambientalismo deixou de ser visto como trabalho de preservação de um grande zoológico terrestre, surgindo o entendimento da importância do meio ambiente dentro do projeto existencial humano. Com a DUBDH, algo parecido acontece: o olhar sai do leito hospitalar e passa a considerar um mundo muito maior, envolvendo inclusive questões ontológicas.

$\mathrm{Na}$ leitura ética do problema ambiental, Hans Jonas ${ }^{19}$ inaugurou a análise da transgeracionalidade, questionando o Aufklärung como razão infinita exploradora dos recursos naturais. $O$ autor propõe uma ética da responsabilidade com as gerações futuras, evidenciando que o pensamento herdeiro do narcisismo instrumental não consegue compreender criticamente a ameaça de destruição do planeta.

Jonas, percebendo o vazio ético da modernidade, chamou atenção para a responsabilidade em relação às novas tecnologias. Se Kant ordenou sapere aude, Jonas proclamou o conscius aude ("ouse ser consciente, responsável"), convidando o humano a assumir seus atos perante as futuras gerações. $\mathrm{O}$ autor questiona: quais são os efeitos 
colaterais das novas tecnologias? Em $O$ princípio responsabilidade: ensaio de uma ética para a civilização tecnológica ${ }^{19}$, Hans Jonas alarga o conceito de dignidade, ultrapassando o lema kantiano do ser humano como fim em si mesmo.

Em 1966, ele escreve $O$ princípio vida: fundamentos para uma biologia filosófica ${ }^{20}$, em que trata da limitação e da precariedade da vida considerada em seu aspecto biológico. Jonas critica os exageros da época, sobretudo o idealismo, chamando-o de "irreal", e seu outro extremo, o materialismo totalmente limitado. $\mathrm{O}$ autor aborda a tensão entre as perspectivas filosóficas que consideram o orgânico como matéria e o espírito como ideia - para os modernos, o espírito permanece como parte do orgânico e, para os antigos, o orgânico já antecede o espírito. Com os modernos, a vida passa a ser considerada exceção, e a matéria inerte é "pura", imutável, em visão dualista que permeia toda a história. Ora, a única forma de se conhecer a "matéria pura", sem contaminação da vida pela visão "hilozoísta" dos antigos no processo de conhecimento, é a matemática, que trabalha com parâmetros e categorias considerados universais ${ }^{27}$.

Dies irae, dies illa ("Dia de ira, aquele dia") foi o que Jonas quis evidenciar em sua obra. Fecha-se o ciclo. Esse dualismo entre o ser e o não ser, o vivo e o não vivo, confere excesso de poder à humanidade, que regula a própria tecnologia e menospreza parâmetros de agir ético que estejam fora de seu cogito. Contudo, a modernidade cai em sua própria armadilha, uma vez que dissipa esse dualismo, mas em consequência faz surgir o idealismo e o materialismo como campos ontológicos que não podem se misturar. Isso impede a conciliação factível para a ciência, em monismo contraditório que percebe a existência de vida sensitiva em um mundo material que não sente, e que na morte triunfa sobre ela ${ }^{28}$. Assim, segundo Jonas, criam-se de um lado as "ciências do espírito" e de outro as "ciências naturais" para separar os campos do idealismo e do materialismo, respectivamente.

Esse foi o pensamento dos modernos que Jonas ${ }^{20}$ combateu ao abordar a inseparabilidade entre corpo e alma e, assim, entre sensação e vontade, física exterior e vitalidade interior etc. Essa fase, em que o autor dá contornos a uma análise ontológica da vida, preparou o que ele viria a propor depois, com a obra $O$ princípio responsabilidade ${ }^{19}$, na qual critica o modelo tradicional de ética porque fundado dentro dos limites de responsabilidade somente em relação ao ser humano.

Como resposta, Jonas busca integrar elementos ou coisas extra-humanas ${ }^{19}$, reformulando a máxima kantiana para abranger também as futuras gerações, ou seja, agir de forma a preservar a vida na Terra - e tudo o que estiver em função dela no presente e no futuro. $\mathrm{O}$ imperativo kantiano "aja de modo que tu também possas querer que tua máxima se torne lei geral" é questionado por Jonas pelo fato de que a reflexão não é moral, mas lógica, uma lógica do "poder" ou "não poder" da vontade. Segundo o autor, não existe nenhuma contradição em si na ideia de que a humanidade cesse de existir, e dessa forma também nenhuma contradição em si na ideia de que a felicidade das gerações presentes e seguintes possa ser paga com a infelicidade ou mesmo com a não existência das gerações pósteras - tampouco a final, como a ideia contrária, de que a existência e a felicidade das gerações futuras sejam pagas com a infelicidade e mesmo com a eliminação parcial da presente ${ }^{29}$.

Em outras palavras: aja de forma a não acabar com tudo ou, ainda, não coloque em perigo a humanidade, não destrua a possibilidade de vida. Em suma, o que Jonas faz é alargar o conceito kantiano de ética, antropocêntrico, de modo que o ser humano seja não somente fim em si mesmo, mas assimile o compromisso de também tratar desse modo seu entorno e as futuras gerações.

Dentro da responsabilidade do agir humano, Jonas critica a postura que define ou delimita a ciência como banco de dados sem qualquer vinculação moral, sem compromisso com valores e consequências. Tal postura transformou o cientista em máquina de descobertas, em sonhador inconsequente, que só acorda quando vê que sua maravilha, por exemplo a fissão nuclear, foi determinante para construir a bomba atômica usada em Hiroshima ${ }^{19}$.

\section{Cuidado do outro e bioética ambiental}

Logo no prefácio de $O$ princípio responsabilidade, Jonas ${ }^{19}$ recorre ao mito de Prometeu para pensar o uso irrestrito da tecnologia, sem freios éticos, na busca por suposta felicidade. Prometeu simboliza a humanidade da racionalidade instrumental, para a qual o saber se torna o poder supremo sobre a natureza. Os limites do saber são as possibilidades do poder, axiologia que introduz novo relativismo absolutista do poder sobre o fazer.

Dentro desse relativismo, é preciso que uma bússola aponte caminhos. É necessário agir com responsabilidade diante da iminência do mal para poder entender o que é agir bem, projetando o futuro e o dever ser. Jonas aponta perigos do sombrio devir, 
o que nos espera a partir da vivência de hoje, propondo uma "heurística do medo" ${ }^{30}$. Nessa perspectiva, a ética deve abandonar o modelo clássico de utopia e a tendência de concentrar-se na qualidade moral do ato momentâneo em si ao invés de desvendar as consequências tardias no destino ignoto ${ }^{31}$.

Para que pudesse permanecer no presente, sem se preocupar com consequências, a tecnologia criou um "utopismo implícito". Esse utopismo, antes ligado ao imaginário das mitologias, hoje faz a humanidade acreditar que a tecnologia resolverá todos os problemas. Assim, o futuro se torna incerto não só pela escala crescente de uso dos bens disponíveis, mas também pela racionalidade infinita do idealismo humano:

O poder tecnológico transformou aquilo que costumava ser exercícios hipotéticos da razão especulativa em esboços concorrentes para projetos executáveis. (...) A escala inelutavelmente "utópica" da moderna tecnologia leva a que se reduza constantemente a saudável distância entre os objetivos quotidianos e últimos, entre as ocasiões em que podemos utilizar o bom senso ordinário e aquelas que requerem uma sabedoria iluminada ${ }^{32}$.

Jonas está preocupado com o futuro tecnológico, e não propriamente com a eternidade. Nesse ponto, ele se distancia claramente de Platão. O agir pauta-se na própria condição humana, em sua natureza, na natureza das coisas e na relação entre ambas. Com base nisso, pode-se definir o que é bom para a humanidade ou não ${ }^{19}$. No entanto, Jonas chama atenção para como esses conceitos não alcançam os efeitos colaterais da tecnologia. Isso porque, se a ação humana se alargou, adequando-se à técnica moderna, os antigos parâmetros já não são mais seguros ${ }^{16}$.

Dessa forma, cria-se um impasse: a ciência não teria limites, e a ética, que deveria organizá-la, não cumpre seu papel. Sobre esse ponto, Jonas cita o coral de Antígona, que louva os feitos dos humanos, que dominam a natureza e tudo podem, desde que cumprindo os preceitos das leis da terra - as leis da relação de causalidade - e da justiça divina, mas são punidos, tendo o desterro como pena, caso descumpram essas leis. O autor cita esse trecho da peça de Sófocles como um dos primeiros textos a relatar o sentido arquétipo do poder e do fazer, uma nota tecnológica dos instrumentos usados para dominar a natureza ${ }^{19}$.

$\mathrm{Na}$ passagem de Sófocles há uma crença de que a natureza teria força geradora ilimitada, o que leva à conclusão de que a humanidade, por mais que quisesse, não conseguiria alterar seu curso, ou, em outras palavras, a natureza seria inesgotável por sua enorme capacidade de se autorregenerar. Desse modo, Jonas expõe que toda a construção racional humana se deu somente dentro da cidade, e esta se fez ilimitada pela razão instável. Fora da cidade, na natureza, acreditava-se que havia lógica própria, relação de causalidade direta, regida por mistério divino que a humanidade não teria poder para alterar. A natureza, por ter suas próprias leis, deveria ser dominada pela inteligência e a inventividade humana; a ética, própria das cidades, não seria necessária.

$\mathrm{Na}$ cidade, portanto, a inteligência deve casar-se com a moralidade, pois essa é a alma de sua existência ${ }^{33}$. Essa separação entre a natureza inesgotável, como produto fora da cidade, e a ética humana é uma das principais características da ética moderna centrada no indivíduo, segundo a qual a manipulação do meio ambiente é necessidade humana. Essa dominação é sempre voltada para o presente, para o agora, com pressa, sem respeito à natureza, visto que não se precisa dela para entender o pensamento humano ${ }^{19}$.

Não estando vinculada à natureza, mas somente à razão humana, a ética existiria em função da racionalidade. Kant defende que a liberdade gera responsabilidade. Jonas avança e propõe que, dentro da heurística do medo, deve-se colocar limites à liberdade para evitar grandes males que coloquem em risco a sociedade. Portanto, havendo necessidade, pode-se contrariar interesses coletivos para evitar tragédias de extinção em massa.

Preocupado com as gerações futuras, Jonas é espécie de neokantiano que alarga o antropocentrismo a fim de abranger o entorno (meio físico natural e transgeracionalidade), criticando a sociedade moderna e optando pelo interesse coletivo. Para ele, o agir ético individual é totalmente diferente do coletivo. Nesse último, a humanidade descobre que a natureza é vulnerável. Com base nessa consciência, Jonas mostra que o meio ambiente tem leis próprias, mas que sofrem interferência humana, especialmente após a Revolução Industrial e as duas grandes guerras.

Contudo, há dois fatores importantes. Primeiro, o destino humano na Terra depende da preservação da natureza, mas essa é ainda perspectiva antropocêntrica. Segundo, as ações humanas em relação à natureza são cumulativas, pois mesmo que se perdoe o erro do desastre ambiental e humano, a ele se somarão outros novos, sem que haja possibilidade de recomeçar, e isso coloca em risco o próprio devir da vontade como ato singular. A natureza não perdoa, o mal feito é cumulativo, e o perdão moral não resolve 
a transgressão ética. O mal contra a natureza se situa em outra dimensão, que não a do perdão. Por isso, a responsabilidade sobre as tecnologias que impactam a natureza é diferente da responsabilidade moral para com outro indivíduo.

Segundo Jonas ${ }^{19}$, para entender o que está acontecendo com a natureza nos últimos tempos é preciso sair do antropocentrismo e do egoísmo narcisista, reconhecendo nossa ignorância quanto a muitos fenômenos extra-humanos de que dependemos para viver. Saber agir implica reconhecer que não sabemos ao certo qual é o nosso compromisso para com a natureza.

O novo modelo de ação deve considerar muito mais do que o comportamento humano. Há outros elementos que condicionam a vida humana na Terra e que devem ser contemplados para além dos fins instrumentais. A humanidade, com sua visão antropocêntrica de ciência, nunca assumiu o papel de responsável pela natureza, mas é hora de fazê-lo, pois há outra noção de responsabilidade que não concerne ao cálculo do que foi feito ex post facto, mas à determinação do que se tem a fazer ${ }^{34}$.

A responsabilidade deve se voltar para o grupo, para o coletivo, e ao mesmo tempo para o futuro, para a sobrevivência da humanidade. Dessa forma, é preciso projetar a relação humana com a natureza, pois um horizonte relevante da responsabilidade é fornecido muito mais pelo futuro indeterminado do que pelo espaço contemporâneo da ação ${ }^{35}$. Para novos tipos de ação, são necessários novos padrões éticos, que possam agir com previsão e responsabilidade compatíveis para integrar o domínio da própria humanidade, afinal, tudo o que ela transforma acaba por ser gerido por ela ou identificado com a própria condição humana ${ }^{19}$

A responsabilidade transgeracional leva ao questionamento ético. Assim, segundo Jonas, antes de se perguntar sobre que poderes representariam ou influenciariam o futuro, devemos nos perguntar sobre qual perspectiva ou qual conhecimento valorativo deve representar o futuro no presente ${ }^{36}$. O poder tecnológico permitiu um mundo totalmente novo, em que o senso comum se une ao científico diante da popularização de seus objetos. Portanto, a utopia não se tornou projeto poético, que pode ser cantado, como fizeram os gregos. Ela se tornou a possibilidade de um futuro sombrio, e é preciso humildade para reconhecer as múltiplas possibilidades de análise do poder tecnológico, pois somente assim seus desígnios podem ser assimilados.
A razão substituiu o medo, que, por sua vez, substituiu a virtude e a sabedoria. E é por ele que são construídos os modernos sistemas de proteção contra a tecnologia, posto que se trata de saber se, sem restabelecer a categoria do sagrado, destruída de cabo a rabo pelo Aufklärung (Iluminismo) científico, é possível ter uma ética que possa controlar os poderes extremos que hoje possuímos e que nos vemos obrigados a seguir conquistando e exercendo ${ }^{37}$. A partir desse ponto, Jonas apresenta quais seriam as feições de uma ética do medo, sempre voltada ao coletivo e baseada na aplicação da filosofia política, ou seja, da justiça do Estado. Assim, o universalismo do potencial apocalíptico dos grandes males leva a prognóstico coletivo que necessariamente exige o agir responsável para evitar o aniquilamento da humanidade.

Para Jonas, quatro preceitos justificam o elemento do agir dentro da ética: 1) a coletividade, pois é por ela que existe a regra da responsabilidade em relação à filosofia política, isto é, da aplicação da justiça; 2) a humanidade não tem direito ao suicídio; 3) os grandes riscos tecnológicos mostram a soberba e o excesso de conforto da existência humana, e portanto não há necessidade de gerar mais condições para preservar a humanidade; e 4) a existência humana deve ficar a salvo de experiências que a coloquem em risco ou em estado de vulnerabilidade $^{19}$. Como visto, Jonas busca integrar elementos extra-humanos à ética tradicional kantiana, para além da racionalidade instrumental que converteu o sapere aude no princípio de Bacon: saber é poder.

\section{Considerações finais}

Em muitos aspectos, a ciência e a tecnologia atuais e sua relação com a humanidade e a natureza remontam ao Aufklärung. Nesse modelo, a ética está centrada no indivíduo; o Outro é momento segundo do eu, e a natureza, insumo a ser instrumentalizado. Na cultura individualista, a alteridade é percebida como algo secundário.

As graves crises sociais, políticas e, por fim, ecológicas que a humanidade vem enfrentando desde a segunda metade do século $X X$ deixaram a descoberto as fragilidades epistêmicas e éticas do legado da modernidade como um todo e do Aufklärung em particular. Ao atual modelo de produção e consumo, que explora a natureza como objeto externo de recursos ilimitados, soma-se o alto poder de interferência das novas tecnologias na natureza e na vida. Se pela primeira vez na história da 
humanidade somos a geração que tem o potencial de impactar a vida sobre a Terra de modo irreversível, é urgente pensar novas matrizes epistêmicas para a ciência, novos modelos de produção e consumo e novos referentes éticos que contemplem nossa responsabilidade para com a vida do planeta Terra como um todo.

Em momento de crise da racionalidade instrumental, surge o pensamento de Hans Jonas, um dos primeiros filósofos a enxergar que há possibilidades reais de a vida ser extinta do planeta e, por isso, deve-se instaurar nova ética baseada na responsabilidade para com as gerações futuras. Desta forma, Jonas substitui o mote iluminista sapere aude por conscius aude, expressão latina que cunhamos para simbolizar o pensamento jonasiano nesse particular.

Foi necessário sair da sombra da razão instrumental para entender que a ética não pode se limitar aos interesses das atuais gerações. Não podemos agir apenas segundo nosso interesse atual. Há um Outro que nos interpela eticamente, as futuras gerações, para com as quais temos responsabilidade.

Este questionamento da ética das gerações futuras trouxe consigo nova concepção de cuidado do Outro. A abertura para a alteridade é constitutiva das relações humanas; somos constituídos pela relação com o Outro, que é a possibilidade de ser o que sou. O cuidado não é concessão moral do eu, mas resposta ética a interpelação radical. Nessa perspectiva, a própria natureza é integrada na alteridade, deixando de ser objeto inerte para se tornar um Outro diferente do humano, mas de que dependemos para existir. Assim, a bioética deve superar a compreensão casuística que até agora demonstrou para se entender como ética do cuidado da vida, do cuidado do Outro.

\section{Referências}

1. Temple GC. Aufklärung e a crítica kantiana no pensamento de Foucault. Cad Ética Filos Polít [Internet]. 2009 [acesso 9 mar 2019];(14):225-46. p. 227. Disponível: https://bit.ly/39wEnAN

2. Temple GC. Op. cit. p. 228.

3. Smith A. A mão invisível. São Paulo: Penguin; 2013. Edição Kindle.

4. Bacon F. Novum organum. São Paulo: Nova Cultural; 1999.

5. Le Prestre P. Ecopolítica internacional. 2a ed. São Paulo: Senac; 2005.

6. Soares GFS. Direito internacional do meio ambiente: emergência, obrigações e responsabilidades. São Paulo: Atlas; 2001.

7. Soares GFS. Op. cit. p. 44.

8. Mazzuoli VO. Coletânea de direito internacional: Constituição Federal. 10ạ ed. São Paulo: Editora Revista dos Tribunais; 2012.

9. United Nations. Report of the United Nations Conference on the Human Environment [Internet]. Estocolmo: ONU; 1972 [acesso 9 mar 2019]. Disponível: https://bit.ly/324Js00

10. Brasil. Decreto no 5.472, de 20 de junho de 2005. Promulga o texto da Convenção de Estocolmo sobre Poluentes Orgânicos Persistentes, adotada, naquela cidade, em 22 de maio de 2001. Diário Oficial da União [Internet]. Brasília, 21 jun 2005 [acesso 9 mar 2019]. Disponível: https://bit.ly/3g4Luml

11. World Commission on Environment and Development. Our common future. Nova York: Oxford University Press; 2009.

12. Trindade AAC. Direitos humanos e meio ambiente: paralelo dos sistemas de proteção internacional. Porto Alegre: Fabris; 1993.

13. Morand-Deviller J. Os territórios do direito: reflexões sobre a generalidade e a impessoalidade da regra de direito. In: Marques CL, Medauar O, Silva ST, coordenadores. O novo direito administrativo, ambiental e urbanístico: estudos em homenagem a Jaqueline Morand-Deviller. São Paulo: Editora Revista dos Tribunais; 2010. p. 62-9.

14. Shelton DL. Developing substantive environmental rights. J Hum Rights Environ [Internet]. 2010 [acesso 27 jul 2020];1(1):89-120. Disponível: https://bit.ly/2BE6YYu

15. Leite JRM, Ayala PA. Dano ambiental: do individual ao coletivo: extrapatrimonial. 3a ed. São Paulo: Editora Revista dos Tribunais; 2010. p. 23.

16. Lucht M. Does Kant have anything to teach us about environmental ethics? Am J Econ Sociol [Internet]. 2007 [acesso 3 mar 2019];66(1):127-50. DOI: 10.2307/27739624

17. Ferry L. A nova ordem ecológica: a árvore, o animal e o homem. Rio de Janeiro: Difel; 2009. p. 26.

18. Rolston H III. Critical issues in future environmental ethics. Ethics Environ [Internet]. 2007 [acesso 9 mar 2019];12(2):139-42. Disponível: https://bit.ly/3eYZJba

19. Jonas H. O princípio responsabilidade: ensaio de uma ética para a civilização tecnológica. Rio de Janeiro: Contraponto; 2006.

20. Jonas H. O princípio vida: fundamentos para uma biologia filosófica. Petrópolis: Vozes; 2004.

21. Agamben G. Profanações. São Paulo: Boitempo; 2007.

22. Levinas E. Totalité et infini: essai sur l'extériorité. Paris: Kluwer Academic; 2000.

23. Junges JR. Bioética: perspectivas e desafios. São Leopoldo: Editora Unisinos; 1999. 
24. Beauchamp TL. Principlism in bioethics. In: Bermúdez PS, Seoane AJ, editores. Bioethical decision making and argumentation. Coruña: Springer; 2016. p. 1-16.

25. Fischer ML, Cunha T, Renk V, Sganzerla A, Santos JZ. Da ética ambiental à bioética ambiental: antecedentes, trajetórias e perspectivas. Hist Ciênc Saúde Manguinhos [Internet]. 2017 [acesso 9 mar 2019];24(2):391-409. DOI: 10.1590/s0104-59702017000200005

26. Organização das Nações Unidas para a Educação, a Ciência e a Cultura. Declaração universal sobre bioética e direitos humanos [Internet]. Paris: Unesco; 2006 [acesso 9 mar 2019]. Disponível: https://bit.ly/2HznRCP

27. Comte-Sponville A, Ferry L. A sabedoria dos modernos: dez questões para o nosso tempo. São Paulo: Martins Fontes; 1999.

8. Jonas H. Op. cit. 2004. p. 26.

29. Jonas H. Op. cit. 2006. p. 47.

30. Zirbel I. Pensando uma ética aplicável ao campo da técnica: Hans Jonas e a ética da responsabilidade [Internet]. 2005 [acesso 24 set 2019]. Disponível: https://bit.ly/2X12fHw

31. Jonas H. Op. cit. 2006. p. 22.

32. Jonas H. Op. cit. 2006. p. 63.

33. Jonas H. Op. cit. 2006. p. 34.

34. Jonas H. Op. cit. 2006. p. 167.

35. Jonas H. Op. cit. 2006. p. 44.

36. Jonas H. Op. cit. 2006. p. 64.

37. Jonas H. Op. cit. 2006. p. 65.

\section{Participação dos autores}

Ambos os autores delimitaram o tema, estruturaram a argumentação, desenvolveram o estudo crítico sobre Kant e Jonas, sistematizaram as conclusões, realizaram a revisão crítica do conteúdo e aprovaram a versão final do texto. Castor Bartolomé Ruiz contribuiu com a análise filosófica dos conceitos e Joelson de Campos Maciel desenvolveu argumentações sobre a bioética ambiental em sua dimensão jurídica.

\section{Correspondência}

Castor Bartolomé Ruiz - Rua Tancredo Neves, 469, Fátima CEP 92200-600. Canoas/RS, Brasil.

Castor Bartolomé Ruiz - Doutor - castorbartolome@terra.com.br

(iD) $0000-0002-6826-1560$

Joelson de Campos Maciel - Doutorando - joelson.maciel@mpmt.mp.br

(iD) $0000-0003-2767-4542$

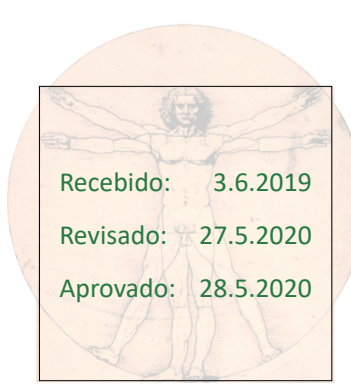

